\title{
ORIGENS, DESENVOLVIMENTO E ASPECTOS DO CORONELISMO
}

\author{
ORIGINS, DEVELOPMENT AND ASPECTS OF COLONELISM
}

\author{
Janaina Florêncio de OLIVEIRA ${ }^{12}$
}

RESUMO: Pretendemos, por intermédio da reflexão aqui contida, estudar alguns aspectos do coronelismo, a fim de compreender como esse sistema acarretou consequências negativas à história política do Brasil. Sendo mais específica, o presente trabalho se concentra em analisar as origens, os elementos que contribuíram para o desenvolvimento da estrutura coronelista e as características dos coronéis. Além disso, essa análise tem como propósito demonstrar como esse sistema conseguiu se perpetuar ao longo da história, porém sob novo formato e nome. Nesse sentido, recorremos à literatura, em especial ao livro do literário Jorge Amado (19122001), Gabriela cravo e canela (1958), e à ciência política, por meio dos livros Coronelismo, enxada e voto (1948) de Victor Nunes Leal (1914-1985) e O mandonismo local na vida política brasileira (1957) de Maria Isaura Pereira de Queiroz.

PALAVRAS-CHAVE: Coronelismo. Origem. Perpetuação política. Clientelismo.

ABSTRACT: We intend, through the reflection contained here, to study some aspects of coronelism, in order to understand how this system brought negative consequences to the political history of Brazil. Being more specific, the present work aims to analyze the origins, the elements that contributed to the development of the coronelist structure and the characteristics of the colonels. In addition, this analysis aims to demonstrate how this system has been able to perpetuate itself throughout history, but under new format and name. In this sense, we turned to literature, especially to the novel Gabriela cravo e canela (1958) by Jorge Amado (1912-2001), as well as to political science through the books Coronelismo, enxada e voto (1948) by Victor Nunes Leal (1914-1985) and O mandonismo local na vida politica brasileira (1957) by Maria Isaura Pereira de Queiroz.

KEYWORDS: Coronelism. Origin. Perpetuation political. Clientelism.

\section{Introdução}

Este trabalho visa analisar, ainda que introdutoriamente, alguns aspectos do coronelismo, mais especificamente naquilo que toca as suas origens, características dos coronéis e elementos que contribuíram para o desenvolvimento desse sistema. É deveras importante compreender o sistema coronelista, pois ele desencadeou uma série de mudanças

${ }^{1}$ Universidade Estadual Paulista (Unesp), Faculdade de Ciências e Letras, Araraquara - SP - Brasil. Graduanda em Ciências Sociais. E-mail: janaina.florenciooliveira@gmail.com. 
que movimentou o rumo social e político do Brasil, devido a sua estrutura repleta de atitudes patrimonialistas, a qual culminou e contribuiu para o desenvolvimento de uma cultura brasileira, abrindo margem para a corrupção, em consequência de confundir o campo publico com o privado, definido por Sérgio Buarque de Holanda, em Raízes do Brasil (1996), como sendo a principal característica da população brasileira, isto é, dos homens cordiais. Além dessas mudanças, mais alguns elementos contribuíram para o desenvolvimento do sistema coronelista, por exemplo: a política dos governadores, coadjuvante na perpetuação da corrupção na vigência do sistema coronelístico; os benefícios econômicos advindos de heranças e comércio e, por último, a posse de parentelas que contribuíram para a proteção das fortunas e também na garantia da segurança política. Todos esses elementos estão descritos ao longo do desenvolvimento deste trabalho e auxiliaram na compreensão de como esse sistema conseguiu se perpetuar ao longo da história, porém transfigurado em outro molde nos dias atuais.

O presente trabalho também constitui suas reflexões se inspirando na literatura de um grande escritor brasileiro, Jorge Amado, que retrata muito bem esse período da Velha República, principalmente, o coronelismo. A presença da literatura em nossa reflexão é porque ela tem muito a dizer sobre a história do Brasil. O livro utilizado para enriquecer nossa exposição, bem como elucidar este período histórico foi: Gabriela cravo e canela (1958) (AMADO, 1978). Por fim, acompanhada da análise literária, este trabalho se desenvolveu também a partir de autores extremamente relevantes à ciência política, os quais, dentre outras coisas, contribuíram para o entendimento do mandonismo local praticado pelos chefes municipais. Tais autores são: Victor Nunes Leal, autor de Coronelismo, enxada e voto (1948) (LEAL, 1975) e Maria Isaura Pereira de Queiroz (1976). Autora de O mandonismo local na vida política brasileira e outros ensaios (1957).

\section{Origens do coronelismo}

O coronelismo no Brasil tem suas origens antes do país ser proclamado uma república, inclusive, os indícios de sua emersão vêm desde a época Imperial, quando prevalecia um sistema no qual se manifestam: mandonismo, filhotismo e a transferência informal de poder por herança (LEAL, 1975). Todavia, seu florescimento, de fato, se deu com a proclamação da primeira república. Isto posto, podemos afirmar que conhecer o coronelismo é também conhecer a vida política do interior do Brasil, pois esse sistema se desenvolve no país como uma forma específica de poder político, uma manifestação do poder público unido com a 
influência particular dos chefes locais, os donos de terras ou, como foram nomeados, coronéis (LEAL, 1975). Corroborando a explicação de Leal, Maria Isaura Queiroz destaca: “Os coronéis assim são chamados devido a Guarda Nacional, que foi criada para defender a constituição desde a época do Império, além de contribuir com a preservação da ordem impedindo revoltas." (QUEIROZ, 1976, p.172). A Guarda Nacional era composta pelos chefes locais e seus títulos e hierarquias eram estabelecidos conforme o prestígio econômico de cada chefe, portanto, vale ressaltar que o posto mais alto era o de coronel. Embora a guarda nacional tenha sido suprimida após a proclamação da república, ainda assim, a autoridade dos coronéis não só permaneceu, mas também se intensificou após a reestruturação política desencadeada pela Constituição de 1891 (QUEIROZ, 1976).

A constituição de 1891 foi a segunda elaborada no Brasil, entretanto, a primeira do sistema republicano que inaugurou, junto com o novo sistema, uma série de mudanças e alterações, transformando o rumo social e político do Brasil, pois seus artigos foram totalmente reformulados em comparação a primeira Constituição pensada para o país. No que se refere ao fato destas mudanças trazerem melhorias ou prejuízos ao panorama institucional brasileiro, só uma profunda observação da continuidade histórica brasileira pode produzir conclusões mais precisas. Contudo, este é um assunto complexo que não corresponde ao foco deste trabalho e, além disso, são necessárias inúmeras pesquisas para abordar satisfatoriamente esta temática.

Depois de fazer tais observações, nos concentraremos em quatro mudanças que o sistema político da Velha República promoveu: 1) a instauração do sistema presidencialista; 2) a definição de três poderes: o Legislativo, Executivo e Judiciário, abolindo o poder Moderador da época do império; 3) as províncias passam a ser estados, e os estados passam a se organizar de forma que fique assegurada tanto a sua autonomia quanto a dos municípios em tudo quanto respeite ao seu peculiar interesse; 4) Estado e religião são apartados e o Brasil é declarado um país laico, no qual os indivíduos podem professar a religião que escolherem ou optar por não exercer nenhum dogma religioso e 5) o fim do voto censitário, que definia quem poderia votar segundo sua renda (BALEEIRO, 2012).

Dentre as numerosas reformas decretadas pela nova constituição, uma das que pode ser considerada notória para se entender o coronelismo e, consequentemente, as ações dos coronéis, foi à promulgação da autonomia dos municípios e a ampliação do direito de voto por meio do sufrágio universal, ou seja, não era mais necessário ter determinada renda para votar, inclusive, todo cidadão brasileiro naturalizado, alfabetizado, não militar, não consagrado a alguma ordem religiosa e não mendigo tinha o direito ao voto garantido. Este 
fato possibilitou o abuso do poder por parte dos coronéis, já que, agora, tinham carta branca para captar mais votos da população das regiões nas quais eles comandavam.

\section{Principais características do coronel}

Os coronéis eram os chefes das regiões do interior do Brasil que monopolizavam o pólo econômico e político de determinada região, entretanto, a figura do coronel não se caracteriza apenas por ser um fazendeiro detentor de grande riqueza em terras, mas também, segundo Leal, os chefes municipais nem sempre são autênticos "coronéis", porque “[...] a maior difusão de ensino superior no Brasil espalhou por toda parte médicos, advogados no qual a figura dessas profissões unidas a uma aptidão para o comando, os capacitavam à chefia." (LEAL, 1975, p.23). A fim de entender mais profundamente as características dos coronéis, podemos recorrer à literatura, em especial, a obra Gabriela cravo e canela do grande literário Jorge Amado, em que é retratado o romance entre uma retirante e um estrangeiro sírio nomeado Nacib. Jorge amado traz como cenário para essa história o sistema coronelista no qual aborda os detalhes desse sistema e traz inúmeros personagens coronéis. Em uma das passagens deste livro, Jorge Amado também discorre sobre os diferentes tipos de coronéis e compartilha alguns aspectos do pensamento de Leal, principalmente quando se refere ao fato de os chefes municipais nem sempre serem "autênticos coronéis", no livro Gabriela cravo e canela, por exemplo, há o fenômeno dos coronéis de "jagunço":

O Doutor não era doutor, o Capitão não era capitão. Como a maior parte dos coronéis não eram coronéis. Poucos, em realidade, os fazendeiros que nos começos da República e da lavoura do cacau haviam adquirido patentes de Coronel da Guarda Nacional. Ficara o costume: dono de roças de mais de mil arrobas passavam normalmente a usar e receber o título que ali não implicava mando militar e, sim, no reconhecimento da riqueza. João Fulgêncio que amava rir dos costumes locais, dizia ser a maioria deles "Coronéis de Jagunço", pois muitos se haviam envolvido nas lutas pela conquista da terra. (AMADO, 1978, p. 29).

Portanto, muitos chefes municipais só são "coronéis" porque devem a este fator a obtenção de aliados políticos advindos dos verdadeiros coronéis, parentes e afins, questão destacada tanto no livro de Leal quanto na obra de Jorge Amado. Contudo, independentemente da via que utilizaram para se tornar chefes locais, seja por lutas na conquista da terra, seja por uma profissão bem reconhecida aliado a aptidão de comando, logo que os coronéis consolidam sua liderança e poderio sobre determinada região, rapidamente 
alcançam uma vasta fortuna política, e na sede por mais poder e riquezas buscam ocupar uma posição administrativa ou uma deputação estadual ou federal. Pelo fato de na maioria das vezes conseguirem realizar tal feito, para não ter que abandonar suas terras a ponto de ficarem desprotegidas e sem comando, acaba por transformar a sua propriedade em um sistema de exploração agrícola no qual o coronel deixa um indivíduo responsável por suas posses. Esse indivíduo, por sua vez, tem a função de intermediar as relações entre o proprietário e os trabalhadores rurais. Leal, em seu livro Coronelismo enxada e voto, chama este tipo de ação de absenteísta, apontando que tal manobra era muito perigosa.

Outra característica emblemática da figura do coronel - reforçando o abuso de poder por parte dos chefes municipais e que, em geral, pode ser encontrado em todos os coronéis - é a tendência de serem chefes de grandes parentelas, ou seja, detinham um vasto grupo de parentescos constituídos de inúmeras famílias unidas tanto por laços sanguíneos quanto por casamentos arranjados, bem como por "compadrios" (QUEIROZ, 1976, p.184). Os casamentos entre as pessoas das mesmas parentelas tinham como propósito a conservação da fortuna e do mandonismo local, mas, principalmente, tinham o intuito da preservação da herança, pois essa lhes garantia a perpetuação do poder e prestígios, bem como o impedimento dessa fortuna migrar para pessoas estranhas mediante casamentos fora das parentelas, ocasionando a divisão da fortuna.

Aliás, estas famílias eram tão vastas que muitas nem se encontravam na mesma região que o coronel habitava, porém estavam unidas por diversos laços por conta do mesmo interesse sociopolítico e econômico. A parentela inteira do coronel, na maioria das vezes, tinha o mesmo nível socioeconômico, auxiliando assim, um ao outro nos negócios. Os negócios e o comércio - sejam de gado, plantações, lavras variadas ou até mesmo quitandas e centros de conveniência - são de extrema relevância tanto para a construção do coronelismo quanto para a fundamentação da figura do coronel, pois foram as atividades lucrativas que levaram os chefes de estados a ascensão sociopolítica. Alcançar estas posições garantia vantagens, pois ao estarem bem estruturados pela fortuna obtida tanto através da via da herança quanto por meio do comércio; o coronel tinha a possibilidade de realizar favores assim como formar clientelas. Isso traz como consequência benefícios ao coronelista, porque ao existir indivíduos "devendo favores" aos coronéis estabelece-se uma relação na qual o devedor tenha sempre que obedecer e ser leal ao credor. Isso geralmente acabava rendendo bons votos aos coronéis, principalmente votos advindos dos roceiros os quais projetavam no coronel um homem rico que, nos momentos de dificuldades, poderia lhe ser solicitado 
favores, acordando como pagamento trabalho gratuito na terra, ou em troca do seu salário e inclusive em forma de voto, fenômeno denominado historicamente como voto de cabresto ${ }^{3}$.

Todos esses benefícios eram adquiridos devido ao acumulo de riquezas através do comércio, esse sistema beneficiava até mesmo quem não era ainda coronel, pois bastava que alguém vindo de fora com capital se alojasse em determinada região e ali fundasse um comércio, essa atitude abria portas e caminhos que podiam levar à chefia política, haja vista que um simples comerciante "[...] ligava a camada mais elevada à camada 'média', e também a camada inferior, assim, ocupava o comerciante uma posição-chave que o guindava facilmente ao posto de cabo eleitoral, e, ampliando sua fortuna, em breve se incluiria entre os coronéis locais.” (QUEIROZ, 1976, p. 196).

Para além dos requisitos econômicos, outra característica presente nos coronéis que se tornou algo cultural no coronelismo era a postura que incumbiam a si mesmo como dominadores, "durões", estabelecedores de ordens. Em outras palavras, eram verdadeiros monarcas, pois dominavam determinadas regiões, nas quais estabeleciam suas próprias regras e ditavam as leis. A justiça da região era exercida segundo o que o coronel considerava justo, ou seja, se algo escapasse aos seus olhos ou se algo ocorresse diferente daquilo que planejava, a correção vinha por meio de suas próprias mãos, ou das mãos dos capangas a seu serviço. A justiça dos coronéis correspondia àquele famoso ditado popular: "olho por olho, dente por dente". Para explicar essa postura assumida pelos coronéis, Queiroz utiliza um termo cunhado por Max Weber:

\begin{abstract}
Assim, do pequeno chefe político local ao grande chefe nacional, apresentavam os coronéis, em graus diferentes, essa virtude indefinível que Max Weber denominou "carisma" - conjunto de dotes pessoais que impõe um indivíduo aos outros, fazendo com que estes lhe obedeçam, tornando suas ordens indiscutíveis justamente porque emanam dele. O carisma era, segundo Max Weber, a virtude dos caudilhos; todo coronel, pequeno ou grande, era um caudilhete ou um caudilho. (QUEIROZ, 1976, p. 198).
\end{abstract}

Era tão importante encarnar este "carisma" que eles concebiam tais características carismáticas como qualidades indispensáveis para se tornar um verdadeiro chefe de região, portanto, no momento de escolher o seu substituto, muitas vezes a liderança não era passada

\footnotetext{
3 Votar em um candidato indicado por um coronel não é aceitar passivamente a vontade deste, é dar conscientemente um voto a um chefe poderoso, de quem já se obteve algo, ou se almeja obter algo. O voto é, pois, consciente, mas orientado de maneira diversa do que o voto de um cidadão de sociedade diferenciada e complexa, no primeiro caso, o voto é um bem de troca, no segundo caso, o voto é a afirmação pessoal de uma opinião [...] Seria necessário se reestudar as relações coronel eleitores, para se desvendar o verdadeiro sentido do chamado "voto de cabresto", durante a Primeira República. (QUEIROZ, 1976, p. 182).
} 
de pai para filho, justamente por causa da falta deste "carisma". É nesse momento que a parentela ganha uma importância para além dos fatores econômicos e políticos, pois, na falta de um filho dotado das qualidades necessárias para desempenhar o papel de chefe, o coronel se volta a sua parentela e escolhia aquele que mais se aproxima ou tinha o carisma coronelista. Esse processo de escolha era realizado através de uma reunião entre os chefes da parentela que, além do carisma, também consideravam os bens e fortuna do parente. Para ilustrar melhor este "carisma" assumido pelos coronéis, o literário Jorge Amado narra o trecho da vida de um velho fazendeiro da cidade de Ilhéus imbuído destas características e chama este personagem de coronel Ramiro:

\begin{abstract}
Era seco e resistente, e em seus olhos pequenos conservavam um brilho de comando, de homem acostumado a dar ordens. Sendo um dos grandes fazendeiros da região, fizera-se chefe político respeitado e temido [...] de dois em dois anos mudava o intendente, em eleições a bico de pena, mas nada mudava em realidade, pois quem continuava a mandar era mesmo Coronel Ramiro. (AMADO, 1978, p. 65).
\end{abstract}

Retomando nossa discussão sobre os coronéis e suas parentelas, dentre todos os benefícios que esta relação social trazia aos chefes regionais, podemos destacar a vantagem das garantias políticas, pois os coronéis elegiam cargos aos próprios parentes e, ao estabelecer essa solidariedade interna, não correriam o risco de serem traídos. Sérgio Buarque de Holanda, em Raízes do Brasil, mais especificamente no início do quinto capítulo já enfatiza os males da interpretação do Estado como uma ampliação da família, nas próprias palavras do autor: "[...] não existe, entre o círculo familiar e o Estado, uma gradação, mas antes uma descontinuidade e até uma oposição [...] é possível acompanhar, ao longo de nossa história o predomínio constante das vontades particulares." (HOLANDA, 1996, p.141-146). Com isso, ao aliar as esferas da política, da economia e das parentelas, bem como gerenciando suas regiões de influência, os coronéis organizavam o funcionamento da sociedade brasileira como um todo, comandando-a segundo a sua vontade e interesses.

É importante nos determos um pouco mais nas questões políticas, pois o coronel se caracteriza justamente pela conquista e exercício do poder político. É deveras importante compreender que o domínio que o chefe de município exercia sob determinada região não se dava apenas pela posse de uma grande fortuna, ou pelo fator econômico e parentela, porém sua possibilidade de perpetuar sua soberania se dava por meio daquilo que Karl Marx e Friedrich Engels, na obra $O$ manifesto do partido comunista, definiram como a contradição que permeia a história de todas as sociedades, ou melhor, nas próprias palavras dos autores: 
"A história de todas as sociedades até hoje existentes é a história das lutas de classes.", em resumo, a contradição entre opressores e oprimidos (MARX; ENGELS, 2010, p.40). Com isso, a soberania que os coronelistas exerciam sobre os trabalhadores rurais lhes rendiam bons votos de cabrestos, ou seja, o coronel através da exploração do roceiro acumula mais poder, bem como a garantia da perpetuação desse poderio político e econômico. Pois, como já mencionado, os roceiros viam no coronel um benfeitor que os auxiliava em momentos de dificuldade, devido ao fato de o roceiro ser pouco alfabetizado, não tendo assim contato com jornais e revistas e tão pouco com assistência médica - quando recebia tal auxilio do chefe de município por habitar em suas terras, consideravam que estava lhe devendo um favor e em troca lhe rendia trabalho gratuito ou votos.

São complexas todas as nuances que envolvem a manipulação do voto, primeiro porque existe muita deturpação no sistema eleitoral brasileiro dessa época. Leal confirma isso ao argumentar que "[...] a corrupção eleitoral tem sido um dos mais notórios e enraizados flagelos do regime representativo no Brasil.” (LEAL, 1975, p.240). No que toca o período da primeira república, as duas maiores falsificações que ocorriam nas eleições era a prática das eleições de bico de pena, no qual a junta apuradora de votos inventava nomes, ou acrescentavam nomes de pessoas já falecidas para arrecadar mais votos, e, a segunda defraudação acontecia nas câmaras legislativas, responsáveis pelo reconhecimento de poderes e a legitimidade das eleições, esse tipo de fraude também ficou conhecido como depuração e degola, pois se decidia arbitrariamente, no final das eleições, se a candidatura era legitima ou não, sendo assim, quando alguém do partido de oposição se candidatava, na maioria das vezes era desconsiderado, devido a esse sistema ilegal de "degola".

O terceiro motivo que contribuía para a capitação de votos ilegais, a fim de eleger determinados representantes, foi a criação da "política dos governadores" atribuída por Campos Sales, consistindo em um acordo de trocas de favores entre o presidente e os chefes de Estado, estes últimos que, por sua vez, retribuíam o favor do executivo por meio de apoio político no Legislativo.

O resultado final do domínio dos votos pelos governadores, que decidem da composição das câmaras federais e da eleição do Presidente da República, é o compromisso que se estabelece entre o governo federal e os estaduais, com o fortalecimento de todo o sistema. A isto se tem chamado entre nós a "política dos governadores", cujo elo primário é a "política dos coronéis". (LEAL, 1975, p. 244). 
Todo esse sistema coronelista corrupto, no que diz respeito aos desvirtuamentos na forma de capitação de voto, trouxe serias consequências para o Brasil, impregnando-se na cultura e na forma de agir dos indivíduos, fazendo com que a forma coronelística se perpetuasse ao longo das décadas, porém com outro desenho e formato, ainda que os autores citados aqui, Leal e Queiroz, tenham apontado acontecimentos que acarretaram o fim do coronelismo, como por exemplo, a industrialização, a emersão de novas instituições e novos órgãos, inclusive "[...] a lei eleitoral, de 1916, que tirou das Câmaras municipais (e, portanto, dos coronéis que as dominavam) o alistamento eleitoral e a apuração das eleições, passandoos para o poder judiciário.” (QUEIROZ, 1976, p.204). Entretanto, um exemplo da continuidade histórica do coronelismo é o dilema institucional do presidencialismo de coalizão, descrito muito bem por Sérgio Henrique de Abranches, em seu artigo Presidencialismo de coalizão: o dilema institucional brasileiro (1988). No qual o autor dedica uma parte do artigo para se trabalhar às coalizões ${ }^{4}$.

Abranches aponta que o maior perigo da coalizão está no quadro institucional do Estado, o qual, em momentos de crise, pode negligenciar os elementos mínimos articuladores da coligação, deixando-as para serem trabalhadas futuramente. Para impedir que isso aconteça, é necessária a construção de elementos institucionais que possibilitem acordos, nos períodos conflituosos. Ainda assim, o autor expõe que a coalizão pode romper-se de duas formas a) pelo abandono dos parceiros menores, isto é, quando o presidente fica a mercê das lideranças regionais majoritárias; b) pelo rompimento do presidente com seu partido, que o deixa em solitário convívio com partidos minoritários. Desse modo a instabilidade de coalizão pode atingir o presidente no congresso, podendo gerar polarização, que resulta na paralisação decisória. E, quando a instabilidade chega à tona é então que aparecem os vestígios do coronelismo, pois há apenas duas alternativas para a recomposição de uma coalizão de governo: ou o presidente torna-se submisso a vontade do partido, ou enfrenta-o, no entanto, tanto a subordinação ao congresso, quanto a ruptura com a aliança são atitudes antidemocráticas. Nesse sentido é necessário encontrar um mecanismo institucional de mediação de conflitos segundo aponta Abranches, esse mecanismo na velha república foi à política dos governadores. É por essa razão que podemos apontar a reprodução do coronelismo, só que transfigurado em uma nova forma, pois as alternativas para a recomposição de uma coalização só ressalta umas das principais características do

${ }^{4}$ As coalizões são estabelecidas, procurando minimizar os parceiros e maximizando a identidade ideológica. No entanto, em realidades de maior heterogeneidade essa solução é impraticável, organizam-se em contraponto, grandes coalizões, nas quais, prevalece a diversidade ideológica e de parceiros. (ABRANCHES, 1988). 
presidencialismo brasileiro "[...] a alta tendência ao conflito de interesses, expressos nos clientelismos regionais." (ABRANCHES, 1988, p. 31).

Por fim, tendo em vista os elementos analisados, são notórias as consequências do coronelismo para o país, principalmente no que concerne a vida política, pois sua estrutura como apontado por Leal é dominado por uma relação de compromisso entre poder privado decadente e o poder público fortalecido. Esse fortalecimento de poder público imbuído ao poder aquisitivo dos coronéis auxiliados com a extensão do direito ao voto contribuiu, e muito, para o domínio, crescimento e poderio dos líderes regionais. A figura do coronel ficou tão bem delineada que penetrou nas veias da sociedade brasileira, fazendo com que circulasse a cultura coronelística ao longo da história e, hoje, ela pulsa no seio de nossa sociedade, mas sob diversos nomes e formas.

\section{Considerações finais}

Ao fim dessa exposição, é esperado que tenha se estabelecido de forma clara e sucinta, através da utilização da literatura e demais autores da ciência política, o que representou e o que significou o coronelismo para o Brasil, bem como o seu impacto para a vida política e social do país, ou seja, como o sistema coronelista conseguiu se perpetuar ao longo da história, porém transfigurado sob diversos nomes e formas. A fim de atingir tal objetivo, foi traçado de forma breve como se deu a emersão do coronelismo e a nomeação de um coronel, bem como alguns elementos que contribuíram para o seu desenvolvimento, sendo esses fatores: o político, o econômico e a posse de parentelas.

De modo geral, ao analisarmos todos os fatores que contribuíram para o desenvolvimento do coronelismo, é notório que esse sistema deixou muitas marcas na história do país, marcas negativas que permeiam tanto o campo social quanto o político, contribuindo para o crescimento de uma cultura brasileira que abre margem para a corrupção, exemplificada no presidencialismo de coalização, praticado nos dias atuais. Os perigos da instabilidade de coalizão demonstram que o seu rompimento pode afetar o presidente no congresso, e as alternativas possíveis para impedir que isso aconteça ou os meios utilizados para tentar se restabelecer a coalização, traz como consequências sinais do sistema coronelista, apontado por Abranches como sendo a alta tendência aos conflitos de interesses manifestado no clientelismo regional. Diante disso fica claro que realmente as características do sistema coronelista perduraram ao longo da história, no entanto, sob uma nova forma. 
O uso da literatura e dos demais autores da ciência política foi de extrema relevância para a elucidação do tema aqui tratado. No caso da literatura de Jorge Amado, ela auxiliou no quesito de ilustrar o que foi o período coronelista, pois além do autor trazer o coronelismo como cenário da história do livro, ele também criou diversos personagens coronéis, políticos, tal como trabalhadores rurais. $\mathrm{E}$ isso facilita a visualização mais próxima da originalidade histórica, tal quanto à personalidade de cada indivíduo que compôs a época do coronelismo. No que se referem aos autores da ciência política, estes são imprescindíveis para a constatação científica dos fatos abordados, além da compreensão mais profunda e critica desse período.

Dada a importância do tema, tornam-se necessários o desenvolvimento de mais estudos que possam analisar outros campos sociais nos quais as características negativas do coronelismo ainda se reproduzem, para que assim se repense formas de dissipá-las. Nesse sentido, o estudo dos aspectos do coronelismo adjunto as conjunturas atuais é de extrema relevância, não só como um meio de compreender a história do país, mas também de perceber o que a sua configuração implicou e ainda implica para a nossa sociedade.

\section{REFERÊNCIAS}

ABRANCHES, S. Presidencialismo de coalizão: o dilema institucional brasileiro. Dados: Revista de Ciências Sociais, Rio de Janeiro, v.31, n.1, p.5-34, 1988.

AMADO, J. Gabriela cravo e canela. 55.ed. Rio de Janeiro; São Paulo: Record, 1978.

BALEEIRO, A. A constituição brasileira: 1891. 3.ed. Brasília: Senado Federal, 2012. v.2.

HOLANDA, S. B. Raízes do Brasil. São Paulo: Companhia das Letras, 1996.

LEAL, V. N. Coronelismo, enxada e voto: o município e o regime representativo no Brasil. São Paulo: Alfa-Omega, 1975.

MARX, K.; ENGELS, F. Manifesto comunista. São Paulo: Boitempo, 2010.

QUEIROZ, M. I. P. de. O coronelismo numa interpretação sociológica. In: QUEIROZ, M. I. P. de. O mandonismo local na vida política brasileira e outros ensaios. São Paulo: Alfamega, 1976. p.163-216. (Biblioteca Alfa-Omega de Ciências Sociais. Série 1., v.5).

\section{Como referenciar este artigo}

OLIVEIRA, Janaina Florêncio de. Origens, desenvolvimento e aspectos do coronelismo. Rev. Sem Aspas, Araraquara, v.6, n.1, p. 74-84, jan./jun. 2017. e-ISSN 2358-4238. 